Corporación Universitaria del Caribe - CECAR ISSN: 2422 - 085X

Enero - Diciembre 2015

Sincelejo, Colombia
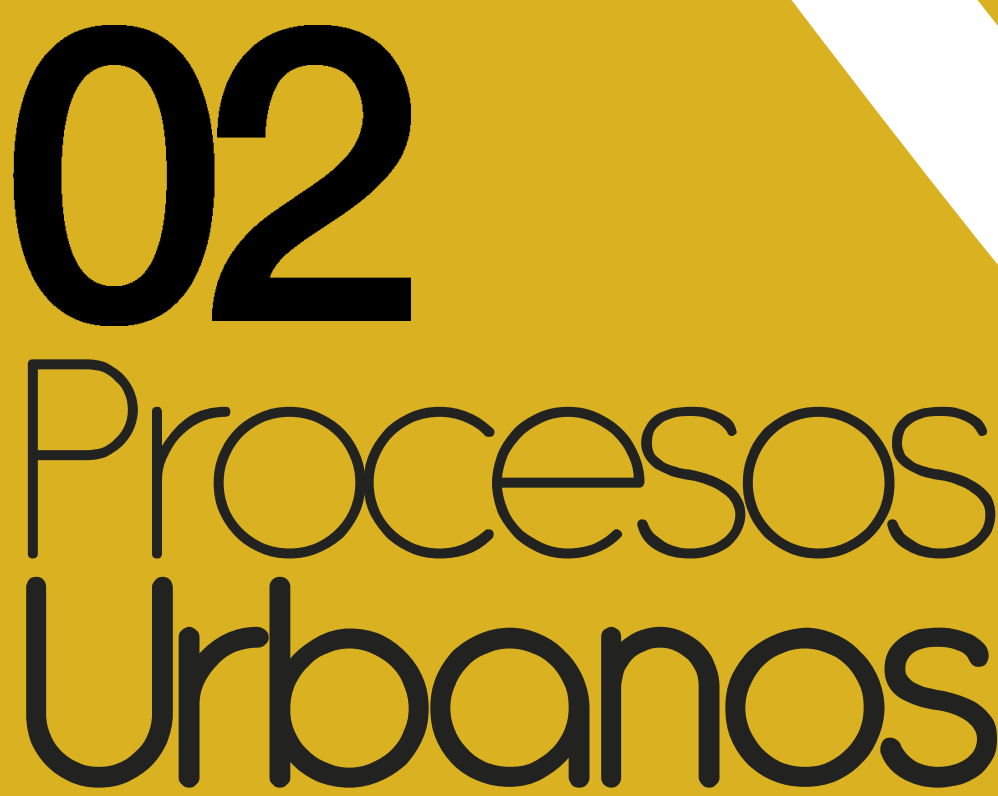

Revista de divulgación científica

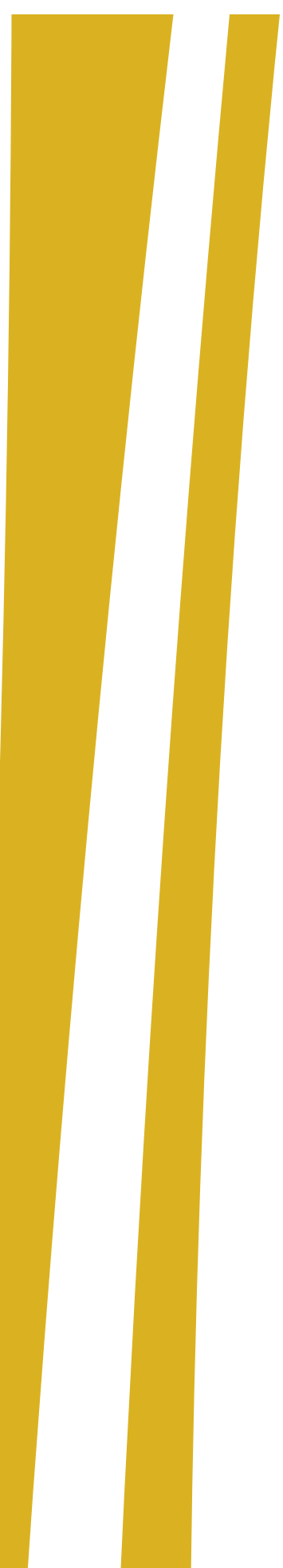

Facultad de Ciencias Básicas, Ingeniería y Arquitectura

Grupo de investigación: Teoría e historia de la arquitectua y la ciudad. 

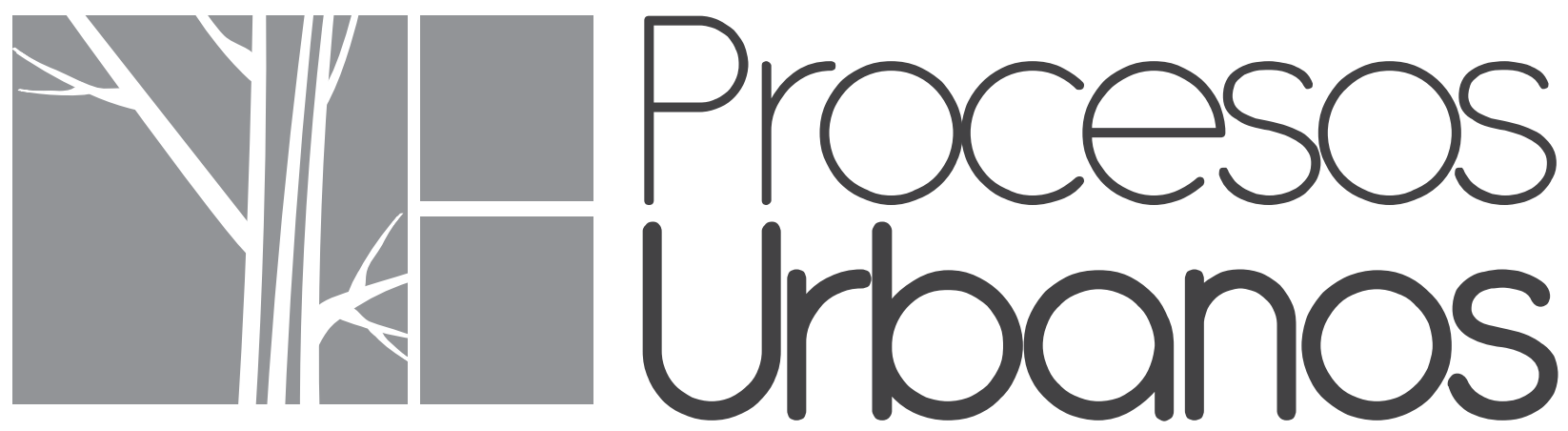

Revista de divulgación científica

Facultad de Ciencias Básicas, Ingeniería y Arquitectura. Grupo de investigación: Teoría e historia de la arquitectura y la ciudad 
Revista Procesos Urbanos

Facultad de Ciencias Básicas, Ingeniería y Arquitectura.

ISSN: 2422-085X (papel)

ISSN: $2500-5200$ (on line)

Sincelejo, enero - diciembre de 2015

\section{Piedad Martínez Carazo}

Rectora

\section{Lidia Flórez de Albis}

Vicerrectora académica

Jhon Víctor Vidal

Vicerrector de Ciencia, Tecnología e Innovación

\section{Pedro Arturo Martínez Osorio}

Editor

\section{Gilberto Martínez Osorio \\ Francisco Martínez Ochoa \\ Coeditores}

\section{Comité Editorial:}

PhD. Alexander Niño Soto. Universidad del Norte

PhD. Jorge Ramírez Nieto. Universidad Nacional de Colombia

Msc. Juan Carlos Pergolis. Universidad Católica de Colombia

PhD. Piedad Martínez Carazo. Corporación Universitaria del Caribe, CECAR

PhD. Emiro F. Martínez. Universidad de York, Canadá

\section{Comité Científico:}

Msc. Gloria Aponte García. UPB, Medellín

PhD. Jorge Gómez Ricardo, Universidad del Magdalena

Msc. Gilberto Martínez Osorio, Corporación Universitaria del Caribe, CECAR

PhD. Alfredo Otero Ortega, Corporación Universitaria del Caribe, CECAR

\section{Editorial CECAR}

Libia Narváez Barbosa

Coordinadora editorial

\section{Eduardo Támara Galván \\ Corrector de estilo}

\section{GRÁFICAS DEL CARIBE S.A.S.}

Diseño gráfico

Cra. 1B No. 40-42 Montería Tel. (57) (4) 7826622 Telefax (57) (4) 7817112

Email: diseno@graficaribe.co

Dirección:

Carretera Troncal de occidente

Kilómetro 1 vía a Corozal

Tel: 280402928040172804018 Ext 1115

www.cecar.edu.co

http://revistas.cecar.edu.co/procesos-urbanos

http://ojs.cecar.edu.co/procesos-urbanos

PROCESOS URBANOS hace parte de:

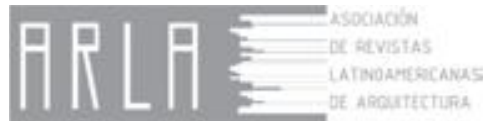




\title{
LA CIUDAD COLOMBIANA ¿FUTURO SIN PASADO?
}

\author{
Colombian cities, a future without a past? \\ Luis Fernando González Escobar² \\ Recibido: 03 de agosto de 2015. Aceptado: 30 de octubre de 2015
}

\section{RESUMEN}

La pregunta por la identidad y la tradición en tiempos de la urbanización, la velocidad y la globalización es la que se plantea el autor para poner en cuestión qué está sucediendo con la intervención urbana en las ciudades colombianas. Se plantea un contexto general sobre las dinámicas del sistema mundo que han conducido a la denominada urbanalización y la manera como en la ciudad colombiana se adoptan de manera a crítica. Frente a lo cual el autor se pregunta si conceptos como identidad y originalidad tienen alguna pertinencia en nuestras realidades urbanas como condición de posibilidad. Una vuelta a la tradición no como regreso al pasado, sino como lectura de las condiciones geográficas, paisajísticas, culturales y de memoria para reclamar una nueva relación pasado-presente-futuro de la ciudad y la arquitectura.

Palabras clave: Urbanización, globalización, espacio público, arquitectura urbana, formas de habitar, identidad, tradición.

\begin{abstract}
The question of identity and tradition in times of urbanization, speed and globalization, is the one the author establishes to question what is happening with the urban intervention in Colombian cities.

It arises a general context of the dynamics of the world system that have led to the so-called urbanalization and how in the Colombian city is adopted in a critical way. Against which the author wonders whether concepts such as identity and originality have any relevance in our urban realities as a condition of possibility.

A return to tradition, not as a return to the past but as a reading of geographic, landscape, memory and cultural conditions. To claim a new past-present-future relationship of the city and architecture.
\end{abstract}

Keywords: Urbanization, globalization, public space, urban architecture, ways of living, identity, tradition.

\footnotetext{
${ }^{1}$ Este texto parte de la conferencia dictada en la inauguración del XXXII Congreso Colombiano de Arquitectura, realizado en la ciudad de Cali, entre el 3 y el 5 de agosto del 2011, organizado por la Sociedad Colombiana de Arquitectos. Como texto es inédito y se ha actualizado para ser publicada en la revista Procesos Urbanos de la Corporación Universitaria del Caribe CECAR, teniendo en cuenta su pertinencia y actualidad temática.

2Profesor asociado, en la actualidad director de la Escuela del Hábitat de la Facultad de Arquitectura de la Universidad Nacional de Colombia, sede Medellín. Arquitecto constructor, con maestría en Estudios Urbano-Regionales y doctorado en historia en la Facultad de Ciencias Humanas y Económicas de la Universidad Nacional de Colombia. 1a mención internacional en la categoría teoría, historia y crítica de la arquitectura, el urbanismo y el paisaje en la XIX Bienal panamericana de arquitectura, Quito BAQ 2014; Mención de honor en la categoría de historia, teoría y crítica de la XXIV Bienal colombiana de arquitectura, 2014 mención de honor en crítica, en la XVII Bienal panamericana de arquitectura SAQ 2010, Quito (Ecuador), noviembre de 2010. Premio nacional de arquitectura, "Carlos Martínez Jiménez", área de investigación en la XVI Bienal de arquitectura, 1998. El último libro publicado es Del alarife al arquitecto. El saber hacer y el pensar la arquitectura en Colombia 1847-1936. Email: Ifgonzal@unal.edu.co
} 
PROCESOS URBANOS - Revista de divulgación científica vol. 2 enero - diciembre 2015 (49 - 57)

Asistimos a la transformación del mundo a un ritmo vertiginoso. La velocidad como medio, en términos del filósofo y urbanista Paul Virilio, ha redefinido desde la economía hasta la vida misma. No solo transforma la realidad, sino nuestra percepción de las cosas. Al punto que la avalancha de fenómenos nos impide tomar distancia de lo que está ocurriendo a nuestro derredor y nos imposibilita sorprendernos de todos los cambios ocurridos en las tres últimas décadas y en cuánto, estos nos han afectado.

Hace un poco más de treinta años se puso en venta el primer computador portátil en el mundo -el llamado Osborne 1 que, por lo demás, pesaba más de 10 kilos y el leve peso de los actuales nos dice también cuánto avanzó la nanotecnología en este mismo lapso-; apenas diez y nueve años nos separa del lanzamiento de la Web la World Wide Web- que popularizó la internet y nos cambió para siempre la vida cotidiana, virtualizándola y configurando el ciberespacio. Esa misma rapidez de los sucesos hace ver esos pocos años como algo tan lejano, pero, a su vez, se vive en un eterno presente que nos obliga a reactualizarnos y dejar pronto atrás cada nuevo elemento que se pone en circulación: facebook, blogger, flicker, twitter, ipad, ipod, iphone, etc. Un presentismo y levedad que determinan las formas de percepción temporal.

Estamos hablando entonces de la avalancha de los últimos años, los que se definen también por dos fenómenos fundamentales: la urbanización mundial y la globalización. El parte-aguas del predominio de los pobladores urbanos sobre los rurales se estimó de manera teórica y simbólica, por parte de unos sociólogos norteamericanos, el día 23 de mayo de 2007. La ONU señaló que a finales del 2010 el 50,5\% de la población planetaria vivía en centros urbanos, y esto equivalía a 3.500 millones de seres humanos. Año en el cual 140 de los 230 países ya tenía la mitad de la población en entornos urbanos.

En buena medida, producto de las nuevas formas de comunicación o de la revolución informática, se derivó una dinámica de interdependencia económica, tecnológica, social y cultural, que se conoce como la globalización. Y, a su vez, derivadas de esas dinámicas de globalización económica, son las que la economista y socióloga holandesa Saskia Sassen denominó "ciudades globales", esto es, grandes áreas metropolitanas donde se concentran las redes de telecomunicaciones y el poder económico fundamentalmente financiero; (Sassen, 1991) pero, por otro lado, Olivier Mongin considera que la condición urbana generalizada determinó el "sistema urbano mundializado que privilegia las redes y los flujos" (Mongín, 2006, p.167), en el que no solo hay ciudades globales, sino que distingue mega-ciudades, metrópolis $y$ megalópolis. De ahí que este mismo autor hable de un "planeta urbano".

Pero en ese planeta urbano y globalizado se expresan unas dinámicas de paisajes homogeneizados, algo que se ha denominado "urbanalización". Francesc Muñoz, acotando el término, señala: "si nos fijamos en el paisaje urbano, vemos cómo ciudades distintas -con historia y cultura diversas, de población y extensión nada comparables, y localizadas en lugares muy diferentes del planeta-, experimentan transformaciones muy similares y acaban produciendo un paisaje estandarizado y común" (Muñoz, 2008, p.11). La urbanalización es el resultado de tres procesos simultáneos: la especialización económica y funcional, la segregación morfológica del espacio urbano y la tematización del paisaje urbano; el mismo Muñoz, registra cuatro requerimientos urbanos que modelan y acompañan este proceso: 1. "la imagen como primer factor de la producción de la ciudad"; 2 . "la necesidad de condiciones suficientes de seguridad urbana"; 3. "la utilización de algunos elementos morfológicos de la ciudad como el espacio público en términos de 'playas de ocio""; y 4. "el consumo del espacio urbano a tiempo parcial, que implica el predominio de comportamientos vinculados a la experiencia del visitante entre lugares más que a la del habitante de un lugar"(Muñoz, 2008, p.67). No obstante, y a pesar de ello, queda un resquicio para la diferencia, el de las "pequeñas diferencias" que aún permite observar ciertas particularidades y rasgos 
particulares frente a la horda de repeticiones homogéneas.

¿Podemos mirarnos en ese espejo mundial? Sin ninguna duda. No fuimos ni somos una ínsula. De muchas maneras somos interdependientes. Ya sea de manera legal - ilegal nos insertamos con el mundo y sus dinámicas globales. Pero aun así tenemos nuestros propios problemas. Y resalto nuestras preocupaciones locales, con sus dinámicas y características, sus particulares expresiones problemáticas que tuvieron a partir de los años de 1980 un momento crucial.

¿En ese marco mundial tan sorprendente en qué estábamos en Colombia? La tendencia mundial de urbanización ya se había experimentado desde tiempo atrás en el país, al punto que para el año de 2005 se calculó que el $74,3 \%$ de la población ya sería urbana. Pero el fenómeno de urbanización era más notable en las cuatro principales ciudades del país, esto es, Bogotá, Medellín, Cali y Barranquilla, las que, para el año de 1951, concentraban apenas el 16\% de la población total del país, pero ya en 1985 representaban el $26,9 \%$ del total poblacional, la que a su vez era el $45,9 \%$ del total de la población urbana. Situación que se mantiene e incrementa desde entonces hasta la primera década del siglo XXI cuando estas mismas cuatro ciudades tiene el $30,4 \%$ del total poblacional, siendo el $60 \%$ de la población urbana.

Así mismo, en los años ochenta del siglo pasado, como ya he señalado, se expresaron fenómenos como "la parálisis del sector productivo con la consecuente crisis económica y de la deuda externa (1985), y el aumento de los niveles de pobreza; las tomas de la embajada de República Dominicana (1980) y del Palacio de Justicia (1985) en Bogotá por parte del grupo guerrillero $\mathrm{M}-19$, que trasladaron el conflicto armado al escenario urbano; los magnicidios de dirigentes políticos afiliados a diferentes tendencias, funcionarios públicos, ministros y periodistas, a manos de grupos de derecha $y$ de narcotraficantes que implantaron la zozobra y el caos urbano mediante la intimidación sicarial y los atentados con bombas" (González, 2010, p.160.
El poeta alemán Höderlin, anotó: "Allí donde está el peligro, allí crece también lo que salva"; nada más cierto para el caso colombiano, pues en una década de profunda crisis también se dieron transiciones cruciales y la emergencia de alternativas que determinaron procesos cruciales en la transformación de la ciudad colombiana en medio de la desesperanza. La combinación de estudios académicos, análisis factuales y reflexiones teóricas sobre la ciudad y su problemática urbana, junto a las reformas políticas implementadas -desde la descentralización administrativa, la elección popular de alcaldes o la Constitución de 1991-, y la normatividad y políticas públicas formuladas -como la Ley de Reforma Urbana- que determinaron aspectos tan fundamentales como la función pública del urbanismo y la importancia que se le otorgaba al espacio público y al equipamiento urbano (González, 2010, p.16), se conjugaron en un proceso complejo y de alguna manera traumático, pero que en su conjunto fueron definiendo una nueva manera de ver la ciudad y lo urbano. La década de 1980 es considerada un periodo de inflexión frente a la complejidad de problemáticas en las que estaba abocada la ciudad y la sociedad no solo colombiana, sino latinoamericana.

En tal sentido, el caso colombiano hay que señalarlo como paradigmático. De la crisis emergieron las propuestas para empezar a transitar de esa ciudad del miedo y el encerramiento a una que le diera lugar a la cultura ciudadana, al espacio público y la inclusión social. Con la elección popular de alcaldes - producto de la elección directa $y$ el surgimiento del voto de opinión- y sus ideas renovadoras, empezó a hacerse visible la ciudad $y$, especialmente, a partir de la dupla Antanas Mockus-Paul Bromberg en Bogotá (1995-1998), se inauguró en el Estado colombiano una visión de la ciudad, lo que en esos momentos quería decir de la sociedad misma, como una problemática cultural y colectiva que le planteaba al gobernante unas exigencias políticas y sociales que rebasaran los recortados marcos -pragmáticos, físicos y económicosdel manejo y la administración de poder que habían significado el devenir de lo político en el país hasta ese momento, de acuerdo con 
PROCESOS URBANOS - Revista de divulgación científica vol. 2 enero - diciembre 2015 (49 - 57)

Ios planteamientos del arquitecto Fernando Viviescas (González, 2010, p.19).

Con la nueva mirada sobre la espacialidad urbana y a la par con las nacientes figuras políticas locales empezó ya a tener relevancia el arquitecto, desde los talleres o colectivos institucionales, las figuras relevantes y reconocidas del escenario local y nacional, las nuevas y emergentes estrellas, además de las convocatorias a concursos públicos, y con ellas, las posibilidades brindadas a los jóvenes diseñadores para presentar las alternativas a cada uno de los temasproblemas urbanos.

Así, en las ciudades colombianas, se construyen los "proyectos detonantes" feo, explosivo y poco amigable nombre, para algo tan pretencioso sin los consiguientes efectos desencadenantes que se pretendían generar-, o las piezas urbanas y arquitectónicas ya en los sectores populares, marginales o periféricos de las ciudades o en los alicaídos centros urbanos, con una estética que, para el primer caso, nunca se había considerado como primordial o necesaria. El derecho a la belleza en los sectores marginales o populares comenzó a hacerse un hecho tangible y reivindicable.

El poder simbólico de lo público volvió a retomarse y a legitimarse ante la sociedad y en los territorios en disputa con la ilegalidad de los actores armados de diferentes enfoques ideológicos. La educación y con ella las nuevas instituciones educativas megacolegios y parques bibliotecas-, que apuntan a una transformación social desde procesos mucho más complejos a largo plazo y no a soluciones inmediatistas y efectistas.

Un tejido urbano de alamedas, senderos o paseos urbanos surgió para hacer una ciudad más humana, la que en el caminar retoma el paisaje urbano cualificado, el que se había negado o empobrecido al viandante cotidiano ante el avasallamiento publicitario y vehicular. Con las alternativas peatonales, las de transporte masivo que aparte de la movilidad también incidieron en la recuperación de grandes sectores urbanos como espacio público o como área de renovación urbana.
Nuevos y significativos espacios públicos - parques temáticos y ambientales, plazas cívicas y culturales, entre otras alternativas-, entre otras realizaciones-, que se caracterizan no solo por las posibilidades estéticas involucradas, sino por la singularidad de las soluciones frente a las realidades locales y ambientales de donde se insertaron algunos de estos proyectos, determinando dinámicas de apropiación y sociabilidad que recuperaron el verdadero significado y la importancia de estos espacios en lo urbano.

Así, de las grandes ciudades -Bogotá y Medellín inicialmente- a los pequeños centros urbanos -desde el Pacífico a la Orinoquía, desde la Amazonía a la Costa Caribe pasando por la zona Andina-, la arquitectura urbana se ha impuesto como un valor incuestionable, tal y como concluyó en el libro Ciudad y Arquitectura Urbana en Colombia, y retomo en extenso en los párrafos siguientes:

Una amplia gama de posibilidades materiales, técnicas y estéticas, en las que sin desconocer el predominio de imágenes arquetípicas internacionales y de modas pasajeras, se tienen proyectos de gran factura y calidad, que responden a las necesidades y demandas de la sociedad urbana, e incluso se transita hacia nuevas propuestas donde se ligan la apropiación y la contextualización, y se relacionan los lenguajes universales con las estéticas configuradas a partir de las búsquedas personales de los arquitectos.

Igualmente $\mathrm{y}$ de manera lamentable, estas arquitecturas de carácter público con un enorme poder simbólico, se deslizan peligrosamente hacia una combinación de ligereza formal y de manipulación política, para ocultar realidades sociales y económicas de las ciudades colombianas. Queda a futuro que, asumidas en sus verdaderas dimensiones, teniendo claras las posibilidades y limitaciones en cuanto la real dimensión del poder transformador de la ciudad y la sociedad, puedan cumplir un papel destacado como ha 
venido ocurriendo en los últimos treinta años.

La ciudad futura demanda de la arquitectura urbana un esfuerzo notable no solo desde la estética y lo simbólico, sino en su sostenibilidad - ausente en muchos casos hasta el presente-, en la capacidad de inclusión social, en el poder ordenador para hacerlas menos caóticas e inequitativas. La perspectiva reclama e induce a pensar que los premios para la arquitectura urbana y los reconocimientos para los dirigentes de la clase política que las han auspiciado se multiplicaran, pero se desearía que ello no fuera un objetivo con pretensiones mediáticas, sino una consecuencia de intervenciones cuyos resultados sean palpables, claros, exitosos, apropiados y como respuesta a las demandas y necesidades sociales urbanas.

Los proyectos que están en proceso en las principales ciudades del país, los que se plantean en el corto y mediano plazo, demandan un gran porcentaje de los recursos del erario público y apuntan a una radical transformación del paisaje urbano, lo que lleva a preguntar si alcanzará para cambiar la imagen de marginalidad que ha dominado hasta el momento. Esto implicaría un paisaje donde los proyectos y piezas urbanas no serán lo excepcional, sino parte del contexto general del cambio social. Obviamente esto no lo pueden precisar ni garantizar las imágenes que se difunden de los proyectos, pero sí direccionar por aquellos arquitectos que han entendido la necesidad de la política y el sentido de lo público, los políticos que han comprendido el poder de la estética y la posibilidad de cambio desde la arquitectura, y la sociedad que ha reclamado y apropiado el derecho a la ciudad y a la arquitectura de calidad (González, 2010, p.251-253).

No hay ninguna duda de la importancia que adquirió el proyecto urbano y el arquitecto en la sociedad colombiana, sus efectos transformadores y la calidad arquitectónica de muchos de los proyectos ejecutados, algo que fue reconocido ampliamente en el mundo. Entre 1981, cuando en la Bienal de Arquitectura de Quito, Germán Samper Gneco recibió una mención por el proyecto del edificio de El Tiempo, hasta el año 2003, cuando le fue otorgada al arquitecto Rogelio Salmona la medalla Alvar Aalto por la Asociación Finlandesa de Arquitectos, los reconocimientos a los arquitectos colombianos en el concierto internacional eran esporádicos. Pero desde el León de Oro otorgado a la ciudad de Bogotá en la Bienal de Venecia en 2006, se multiplicaron los premios y reconocimientos a las entidades y dirigentes gubernamentales y a los arquitectos, en eventos regionales, panamericanos, iberoamericanos 0 europeos. Reconocimiento que implicó también la publicación de numerosos artículos de prensa sobre los efectos de la arquitectura en la sociedad o de muchos proyectos en las revistas especializadas de arquitectura de todo el mundo, para exaltar la calidad intrínseca de la obra, como ha ocurrido con un destacado arquitecto cuya obra ha sido dada a conocer en más de 136 publicaciones del mundo. Aparte de ello hay una evidente internacionalización de los arquitectos colombianos, en la medida que han ganado concursos internacionales 0 , a manera de reconocimiento, forman parte de importantes firmas e, incluso, son llamados directamente para que adelanten sustantivos proyectos en el extranjero.

Quedaría flotando en el aire una pregunta: ¿esa fuerte internacionalización implica una dinámica de banalización? No se pregunta solo por el prurito de estar en contacto con el mundo, sino por la adopción gratuita y acrítica de los lenguajes de moda, como lo señala el arquitecto Álvaro Barrera, frente a la existencia de una corriente a nivel mundial "donde todo se basa en crear formas, independientemente de si la arquitectura funciona o no. Buscan que las formas sean más escultóricas, mientras más se destaque el monumento propio, mejor. No importa que lo rodeen, no importa lo que pase en el planeta" $(2011$, p.2). En ese sentido en nuestro medio se participaría más de aquellas ideas de la urbanalización que en buena medida impera en el mundo, 
PROCESOS URBANOS - Revista de divulgación científica vol. 2 enero - diciembre 2015 (49 - 57)

olvidándonos así de las realidades locales.

Solo al leer la prensa colombiana se deja percibir esa sensación, en los reclamos que le hacen a la arquitectura y a los arquitectos desde otras disciplinas y formas de percibir las problemáticas de la sociedad; por ejemplo, el investigador caribeño Adolfo Meisel Roca, llamó hace unos años la atención sobre copiar o repetir modelos y no responder creativamente a partir de las problemáticas particulares. Posición que adopta al poner en cuestión el tema del mototaxismo, una innovación para la movilidad de los sectores más pobres, que surgió en el municipio de Cotorra (Córdoba) y luego se extendió al Caribe -Sincelejo incluido- y el resto del país, en el que le ve más posibilidades, y no únicamente los problemas que repetidamente se le endilgan, pero cuyo caso no se puede entender, asumir y plantear soluciones si "insistimos en patrones de desarrollo que replican sin consideración seguidos en los países desarrollados".

Otro tanto dejó traslucir el antropólogo Jaime Arocha acerca de la arquitectura de las comunidades afrocolombianas e indígenas del Pacífico colombiano, al comentar y dolerse cómo las escaleras en otros ámbitos son motivo de literatura mientras que aquellas no, ya fueran las de los caminos de la serranía del Baudó, las de los atracaderos de los puertos fluviales en cada pueblo de la selva o las talladas en troncos de los tambos palafíticos de las comunidades embera, para, concluir con las de las comunidades negras que hacían "con tablas anchas para subir hasta la entrada de sus casas de madera, que parecían vivas porque les respondían a los movimientos de sus moradores con chirridos y a los temblores de tierra con balanceos flexibles. Su amplitud y frescura contrastan con las hirvientes cajitas de cemento y teja de cinc que diseñan los arquitectos universitarios de ciudad para el interés social (Espectador 35445, 2011, p.30).

Otro ejemplo de los reclamos que se escuchan, los planteó la bióloga Brigitte Baptiste, directora del Instituto de Investigaciones Biológicas Alexander von
Humboldt. Cuando se habla de la crisis planetaria, el cambio climático y la necesidad de transformar nuestra manera de habitar, de urbanizarnos y hacer arquitectura sostenible, enfatiza en la necesidad de dar respuestas que nos permitan "asumirnos con una identidad global única, con un modelo de desarrollo económico propio y unas capacidades y potencialidades diferentes a los demás países" (Espectador 35439, 2011, p.13); estas palabras, bajo la lupa de ciertos arquitectos globalizados, les parecerían anacrónicas, pasadas de moda y sin razón de ser. Identidad, propio y diferente, son aspectos fundamentales que destaca Baptiste para generar "formas de habitar, producir y gobernar, consecuentes con el carácter único de cada lugar, capaces de incorporar y proyectar el patrimonio natural y cultural propios" (Espectador 35439, 2011, p.13).

Sin desconocer los aportes que algunos arquitectos han hecho y hacen al respecto, en el discurso arquitectónico predominante en la actualidad hay un ir "hacia adelante", que le da la espalda a todo este mundo local en aras de la globalización y en la que además se ha proscrito toda tentativa de mirar hacia el lado y hacia atrás. Conceptos como tradición, identidad o historia son mirados con recelo o de manera determinante, irreflexiva y ortodoxa se descalifican. Hace poco un joven arquitecto sentenciaba en el extranjero: "Responder por la identidad a través de la arquitectura me parece un despropósito [...] El tema de la identidad, poco o diría que no me interesa como búsqueda o instrumento, pensemos que en nombre de la tradición y la identidad se regalan niños, se mata o se tortura...". No sé cómo calificar estas ideas, pues transitan entre la ingenuidad, la ignorancia y la prepotencia.

Cosa curiosa, no sé si de manera consciente o inconsciente, la programación del XXXII Congreso Colombiano de Arquitectura, fue configurada en un sentido lineal, siguiendo el positivismo decimonónico: el primer día la tradición, el segundo día el presente y el tercer y último día, el futuro. iAleluya! el glorioso futuro. Este texto corresponde a los practicantes del tradicionalismo. 
La tradición, de acuerdo con el diccionario de la Real Academia de la Lengua, es un sustantivo femenino, que se refiere a la "trasmisión de noticias, composiciones literarias, doctrinas, ritos, costumbres, etc. hechas de generación en generación", al igual que un "hecho antiguo" trasmitido también de generación en generación, o "la doctrina, costumbre, etc., conservada en un pueblo por trasmisión de padre a hijos". Nosotros seriamos entonces los tradicionalistas, es decir los que practicamos la doctrina filosófica del tradicionalismo, que quiere decir los que ponemos "el origen de las ideas en la revelación y sucesivamente en la enseñanza que el hombre recibe de la sociedad", a la vez que amantes de un "sistema político que consiste en mantener o restablecer las instituciones antiguas en el régimen de la nación y en la organización social".

En su concepción básica, tradición quiere decir donación o legado. Esos legados supuestamente van definiendo caracteres, diferenciaciones y hacen singular a una sociedad determinada. Tradición que formará su patrimonio cultural. Esa forma de concebir la tradición implica una quietud, quedarse en el tiempo, aferrarse a un pasado, muchas veces añorado como glorioso y, por tanto, una edad dorada perdida. Pero no es tan cierto pues aún las tradiciones se inventan, se recrean y se van re-configurando con el transcurso del tiempo.

En tal sentido vale la pena volver a leer y reflexionar lo que un escritor cubano que se formó como arquitecto, Alejo Carpentier, quien murió en 1980 pero que en 1975 expuso en cuatro conferencias en la ciudad de Caracas (Venezuela), reunidas en un texto que sugestivamente se titula "Razón de ser"; en la primera conferencia dice:

Los latinoamericanos de mi generación conocieron un raro destino que bastaría por sí solo, para diferenciarlos de los hombres de Europa: nacieron, crecieron, maduraron, en función del concreto armado. Mientras el hombre de Europa nacía, crecía, maduraba, entre piedras seculares, edificaciones viejas, apenas acrecidas y anacronizadas por alguna tímida innovación arquitectónica, el latinoamericano nacido en los albores de este siglo de prodigiosos inventos, mutaciones, revoluciones, abría los ojos en ámbitos de ciudades que, casi totalmente inmovilizadas desde los siglos XVII o XVIII, con un lentísimo aumento de población, empezaban a agigantarse, a extenderse, a alargarse, a elevarse, al ritmo de las mezcladoras de concreto [...] $Y$, de repente, he aquí que las amodorradas capitales nuestras se hacen ciudades de verdad (anárquicas en su desarrollo repentino, anárquicas en su trazado, excesivas, irrespetuosas en su afán de demoler para reemplazar) y el hombre nuestro, consustancial con la urbe, se nos hace hombre-ciudad, hombre-ciudad-delsiglo-XX valga decir: hombre-Historiadel-siglo $x x$, dentro de poblaciones que rompen con sus viejos marcos tradicionales, pasan, en pocos años, por las más tremendas crisis de adolescencia y comienzan a afirmarse con características propias, aunque en una atmósfera caótica y desaforada (Carpentier, 2007, pp.5-6).

¿Dejó de existir el "hombre-ciudad-siglo $X X^{\prime \prime}$ ? es obvio que debemos tomar distancia, incursionar en nuevas formas matéricas, técnicas y poéticas, pero también que debimos aprender y construir sobre una tradición moderna, siguiendo de esa manera los planteamientos del brasileño Renato Ortiz, quien explica, desde este concepto, las nuevas tradiciones -el futbol, la samba $y$ el carnaval- que identifican al Brasil del siglo XX.

La velocidad de transformación de las ciudades latinas no debería repetir ese ritmo frenético de las mezcladoras del concreto y debería entenderse como un gran valor una arquitectura moderna sobre la cual cimentar las nuevas propuestas. La sociedad capitalista instauró el principio de la novedad, la creatividad y la originalidad, como principios fundamentales. Ir hacia adelante implica una actitud soberbia que viene desde las vanguardias de principios del siglo XX. Hacer tabula rasa y partir de ceros. Desde esa perspectiva la tradición es incompatible con la originalidad. Pero 
PROCESOS URBANOS - Revista de divulgación científica vol. 2 enero - diciembre 2015 (49 - 57)

otra cosa pensaron poetas como el español Vicente Alexaindre, quien al recibir el premio Nobel de Literatura en 1977 apuntó que "cada autor no representa otra cosa que la de ser, como máximo un modesto eslabón de tránsito hacia una expresión estética diferente". Como se ve no es una tradición quietista, sino en proceso, que se cimenta en lo precedente. Algo que no se considera válido en la actualidad donde se desprecia lo precedente y en la que acaso hay una altivez del arquitecto y pasamos del arquitecto demiurgo al arquitecto soberbio.

Hay que proclamarlo, la "razón de ser" del hombre latinoamericano que plantea Carpentier siguiendo una larga tradición nuestroamericanista iniciada con José Martí, no ha muerto y todavía tiene mucho para aportar. No se trata de pensar identidades latinas 0 nacionales fijas, ni miradas folcloristas 0 estereotipos formalistas 0 decorativistas. Tampoco, como se señalaba para el caso de España y su regionalismo crítico, de "fabricar falsas identidades políticas o artefactos exóticos para la sociedad de consumo".

La tradición incluye la geografía, el paisaje, la memoria, la cultura y un amplio etcétera; por ejemplo, ¿Puede escapar el hombre de su paisaje? El individuo, por más que corra hacia el improbable futuro, jamás podrá desprenderse de su ADN. Si algo ha demostrado la tecno-ciencia es dicha imposibilidad. Por esa misma razón ir hacia el futuro no riñe con el pasado. Todo lo contrario. Son compatibles. Basta señalar un ejemplo paradigmático, para seguir los grandes personajes del star system de la arquitectura mundial. El arquitecto Sir Norman Foster cuando proyectó la ciudad futura en Masdar (en Abu Dhabi), donde habrá energía solar y eólica, se reciclará la basura y no habrá emisiones de carbono, se renovó parapetado en las realidades geográficas, paisajísticas y culturales específicas de este territorio del Medio Oriente. A pesar del énfasis en la tecnología, la ciudad tendrá una sensación de regreso al futuro. Sacará muchas ideas de los conceptos tradicionales del diseño urbano del Medio Oriente: callejuelas estrechas para capturar el viento prevaleciente, estanques poco profundos para refrescar el aire, las así llamadas torres de viento que hacen que el aire más fresco baje al suelo $y$ que funcionan como aire acondicionado natural, y celosía ornamental en las ventanas llamada mashrabiya ${ }^{1}$.

Pongo otro ejemplo: el proyecto del norteamericano Thomas Glassford, XipeTótec, en la plaza de Tlatelolco en ciudad de Méjico. Este sería un magnífico ejemplo de un juego de espejos, donde la resignificación de la memoria es permanente sin barrer con el pasado. La presencia prehispánica es evidente con las evidencias arqueológicas de la arquitectura monumental, pero vuelve a estar presente en un lenguaje contemporáneo con esta intervención referida a una "deidad azteca que lograba encarnar la violencia y el renacimiento del lugar" (Espectador 35445, 2011, p.4). El mismo Glassford explica cómo "al principio se había imaginado un velo o piel, y que Xipe Tótec establecía un vínculo con el pasado y la idea de la muerte que trae vida". Esto en un contexto que tiene la impronta de la masacre indígena por los españoles y la violencia en la superposición de la arquitectura hispana sobre lo indígena, pero de igual manera con la masacre de los estudiantes en esta emblemática plaza en 1968, que aparece rememorado en las imágenes pintadas en los vidrios de una fachada moderna.

La obra fue realizada en un cuasicristales, cuya escogencia también marca ese juego de espejos de la memoria junto al mismo espacio, pues "Roger Penrose, físico británico, describió por primera vez el patrón en 1974, o eso pensó. Algunos investigadores descubrieron más tarde que lo que parecía ser nuevo era en realidad antiguo: el mismo patrón aparece en una capilla iraní construida en 1453", es decir en el siglo XV. Ante lo cual Glassford, señala el paralelo: "los españoles pensaron que estaban milenios delante de los aztecas y otras tribus indígenas...solo para más tarde comprender la sofisticación de la sociedad que habían pretendido erradicar".

${ }^{1}$ http://www.Ianacion.com.ar/1111730-avanza-la-ciudad-verde-masdar. 
Es claro que tenemos que replantearnos la relación con la tradición, el pasado, el patrimonio y la historia. Incluso desde la misma academia, pues en las facultades de arquitectura en el país, por ejemplo, la historia es prescindible o con un peso tan relativo que se ha convertido en insustancial. No se trata de volver a un pasadismo, pero tampoco es el insustancial presentismo ni la constante ida hacia adelante las que nos definen como sociedad.

Hay la imperiosa necesidad por equilibrar pasado, presente y futuro para hacer verdaderas ciudades que respondan a nuestras realidades. Frenar el vértigo de la transformación. La huida hacia adelante no puede desmemorizar las ciudades. Memorizarlas tampoco implica la obligación del quietismo o el anacronismo histórico. Hacerlas actuales no implica la concesión facilista a la moda pasajera y snobista.

\section{REFERENCIAS}

Barrera, A. (2011) Toda obra, Bogotá, núm II, abril de 2011. p2.

Carpentier, A. (2007). Razón de ser. Editorial Letras cubanas, La Habana.

González Escobar, L. (2010). Ciudad y arquitectura urbana en Colombia 1980-2010, Editorial Universidad de Antioquia, Medellín.
Meisel Roca, A. (2011). La revolución de las sabanas.

Mongin, O. (2006). La condición urbana. La ciudad a la hora de la mundialización. Paidós, Buenos Aires.

Muñoz, F. (2008). Urbanalización; paisajes comunes, lugares globales. G. G. Mixta, Barcelona.

Sassen, S. (1991). The global city. Princeton University Press, New York, London, Tokyo, Princeton.

Páginas web:

www. lanacion.com.ar/1111730-avanza-laciudad-verde-masdar

Prensa:

El Espectador, Bogotá, núm. 35428, 9 de julio de 2011.

El Espectador, Bogotá, núm. 35445, 26 de julio de 2011.

El Espectador, Bogotá, núm. 35439, 20 de julio de 2011. 